\title{
Apontamentos e reflexões sobre a sexualidade da pessoa com deficiência intelectual
}

\author{
Notes and reflections about sexuality of people with intellectual disability
}

\section{Wallisten Passos Garcia}

Psicólogo, Mestrando em Psicologia pela Universidade Federal do Paraná (UFPR), Curitiba, PR - Brasil, e- mail: wallistenpg@yahoo.com.br

Recebido: 09/04/2011 Received: 04/09/2011

Aprovado: 17/07/2011 Approved: 07/17/2011

\section{Resumo}

Os trabalhos científicos sobre a sexualidade da pessoa com deficiência intelectual são, em sua maioria, teóricos ou direcionados a investigar o pensamento de pais e profissionais e seu modo de proceder. Poucos estudos têm o objetivo de compreender quais são as experiências, necessidades e sentimentos que as próprias pessoas com deficiência intelectual têm frente a sua sexualidade. Este artigo teve como objetivo investigar a compreensão que as pessoas com deficiência intelectual têm a respeito da sua sexualidade. Por meio do método fenomenológico foram entrevistadas pessoas jovens com deficiência intelectual de uma escola especial na cidade de Curitiba, estado do Paraná. A análise dos dados deu-se conforme as premissas estabelecidas pelo método escolhido. Como resultado, os participantes trouxeram suas compreensões e necessidades em relação a três categorias: namoro, experiência sexual e casamento. Discutese que as pessoas com deficiência intelectual têm uma representação e vivência a respeito de sua sexualidade que precisam ser consideradas ao se trabalhar com os mesmos. Evidenciouse a importância de redimensionar os serviços educacionais e terapêuticos voltados a essas pessoas, com base em uma compreensão global das questões relacionadas à saúde sexual da população em estudo, por meio de um trabalho que envolva a equipe médica e educativa, os familiares e principalmente a própria pessoa com deficiência intelectual.

Palavras-chave: Saúde da pessoa com deficiência. Sexualidade. Inclusão social. Psicologia.

\begin{abstract}
The scientific works on sexuality of people with intellectual disabilities are mostly theoretical or directed to investigate the views of parents and professionals and their way of proceeding. Few studies have the aim to understand what are the experiences, needs and feelings that people with intellectual disabilities themselves have before their sexuality. This paper aims to investigate the comprehension that people with intellectual disability have about their own sexuality. Based on the phenomenological method, interviews were done with young people with intellectual disabilities of a special school in Curitiba city, Paraná state. Interviews were analyzed according to the phenomenological method. As a result, the participants brought about their understanding and needs relative to dating, sexual experience and marriage. It is argued that people with intellectual disabilities have a representational and an existential view concerning
\end{abstract}


their own sexuality, which must be considered when one's working with them. The importance of redesigning educational and therapeutic services to intellectualy disabled people, based on a global understanding of all issues related to this population's sexual health, by means of a work that involves educational and therapeutic group, the family and, particularly, the intellectual disability person herself.

Keywords: Health of people with disabilities. Sexuality. Social inclusion. Psychology.

\section{Introdução}

A deficiência mental, atualmente denominada intelectual, é caracterizada pela Associação Americana de Retardo Mental (AAMR, 2006) e a Associação Psiquiátrica Americana (APA, 1994), por limitações significativas no funcionamento intelectual e no comportamento adaptativo, expresso nas habilidades práticas, sociais e conceituais, originando-se antes dos dezoito anos de idade. Porém, neste trabalho, a deficiência intelectual será compreendida como uma construção social (Amaral, 1994; Omote, 1994; Tomazini, 2004), ou seja, uma condição atribuída ou reconhecida nas pessoas que apresentam alguma diferença em virtude da percepção das pessoas que convivem ou mantêm contato com esses sujeitos. Nesta perspectiva, a deficiência não é algo que emerge com o nascimento ou uma enfermidade contraída, mas "é produzida e mantida por um grupo social na medida em que interpreta e trata como desvantagens certas diferenças apresentadas por determinadas pessoas" (Omote, 1994, p. 68). Tem, portanto, relação com o que a sociedade reconhece ou não como normal na conduta dos sujeitos. 0 que diverge das expectativas da sociedade ou foge da normalidade imposta - "o anormal", "o patológico", "o diferente" - é desvalorizado, excluído do meio social. Para Tomazini (2004), à medida que determinados indivíduos se afastam, em virtude de seus atributos, da grande maioria dos seres dos quais são comparados, passam a ser considerados como uma espécie de negação da ordem social.

Conceber a deficiência como construção social implica compreender que nesse modelo os problemas e dificuldades das pessoas com deficiência não estão na própria pessoa, mas na sociedade que cria barreiras atitudinais - preconceitos, estereótipos e estigma - em relação a elas, causando-lhes desvantagem no desempenho de seus papéis sociais.
O estigma é, para Goffman (1988) a característica, uma marca, que torna o indivíduo inferior por possuir determinado atributo que se distancia da imagem que a sociedade em que ele vive tem como normal. A partir do estigma, é possível observar diversas de suas consequências, dentre elas, a que se tende a inferir uma série de imperfeições a partir da "imperfeição" original. No caso da deficiência intelectual, a pessoa referendada pela sociedade como tal, frequentemente é vista a partir do seu estigma ou sua "imperfeição", ou seja, sua "deficiência/ defeito no intelecto". Desse modo, suas atitudes e comportamentos, expressões de sentimentos e desejos, formas de se relacionarem, são sempre vistas a partir do estigma de "deficiente intelectual". Com isso, gera-se uma visão equivocada e preconceituosa a respeito dessas pessoas que, por serem "deficientes em seu intelecto", são colocadas também como deficientes em outras áreas de seu desenvolvimento como, por exemplo, no campo da sexualidade e afetividade.

Especificamente no campo da deficiência intelectual, Pinheiro (2004) realizou uma revisão das pesquisas publicadas sobre a sexualidade desses indivíduos e constatou a presença de poucos estudos relacionados ao tema. Notou-se que grande parte dos trabalhos estavam mais direcionados a investigar o pensamento de pais e profissionais e seu modo de proceder do que enfocar a própria pessoa com deficiência, o que ela conhece, quais são suas experiências, necessidades e sentimentos diante de sua sexualidade. Em outro estudo, com objetivo de analisar o conteúdo da produção bibliográfica na área da saúde sobre a sexualidade dos adolescentes com deficiência intelectual no período de 14 anos, Bastos e Deslandes (2005) constataram também escassez de estudos relacionados ao tema, concluíram que provavelmente decorrente do preconceito ainda existente em relação a essa temática. As autoras 
perceberam que predominam, nos artigos estudados, a constatação de que há um silêncio sobre a sexualidade da pessoa considerada deficiente intelectual, seja dentro da família ou com outros adultos com quem convive. Outro tema que se destacou nos trabalhos pesquisados pelas autoras foi em relação aos comportamentos considerados socialmente inadequados e o abuso sexual, tema relevante e cujo debate ainda é incipiente principalmente no Brasil. Diante destas considerações, da escassez de estudos e de trabalhos que enfoquem a própria pessoa com deficiência intelectual, buscou-se, nesta pesquisa, conhecer, e reconhecer, aspectos relacionados à sexualidade da pessoa com deficiência intelectual, de modo a possibilitar que essas pessoas falassem sobre suas relações afetivas, valorizando suas experiências. $\mathrm{O}$ objetivo desse estudo foi compreender, por meio de suas falas, como a pessoa com deficiência intelectual experiencia sua sexualidade e o significado que ela atribui a esse aspecto, suas representações e vivências afetivas.

\section{Sexualidade e deficiência intelectual}

A sexualidade é um aspecto da dimensão humana importante para a qualidade dos vínculos e relações sociais e afetivas que as pessoas estabelecem umas com as outras. A Organização Mundial da Saúde (OMS) compreende a sexualidade como a energia que motiva a buscar o amor, o contato, a intimidade, se expressa na forma de sentir, das pessoas tocarem e serem tocadas; influencia pensamentos, sentimentos, ações, interações e tanto a saúde física como mental (Egypto, 2003). Nesse sentido, a sexualidade não deve ser entendida como sinônimo de relação sexual ou sexo, pois abrange outros fatores tais como: amizade, namoro, casamento, sentimentos, e todo tipo de relação consigo e com os outros (Katz \& Lazcano-Ponce, 2008). Quando se fala da sexualidade das pessoas consideradas deficientes intelectuais, a literatura aponta algumas crenças que interferem diretamente na forma como são vistas em relação a esse aspecto. Estudos como o de Bastos (2005); Bastos e Fidry (2007); Dall'Alba (2004); Denari (2002); Eastgate (2008); França Ribeiro (2001); Glat e Freitas (1996); Mourkazel (2003); Maia (2001), entre outros, revelam que uma das crenças é de que essas pessoas são desprovidas de sexualidade ou têm esse aspecto incompleto, sendo encaradas como sexualmente infantis principalmente pelos pais que, ao observar a existência da sexualidade, reprimem ou negam. Outra crença é a de que as pessoas consideradas deficientes intelectuais possuem sexualidade exacerbada, descontrolada, exibicionista, quando na verdade não há um reconhecimento, principalmente por parte dos professores e profissionais que trabalham com essas pessoas, de que eles também sentem desejo e prazer e, se orientados, podem aprender a exprimir esse desejo de forma socialmente apropriada. França Ribeiro (2001) acrescenta que a demonstração de afeto pelas pessoas por meio de gestos como abraço, beijo, aperto de mão, são socialmente valorizados e frequentemente relacionados à sexualidade. As pessoas podem demonstrar e retribuir afeto, porém, nem sempre essa expressão afetiva é referendada socialmente para a pessoa com deficiência intelectual privada, em muitos momentos, do toque como expressão desse afeto. Diante dessas crenças, para Denari (2002), inúmeras restrições são impostas às pessoas consideradas deficientes intelectuais, desde a adolescência, em nome de uma ética sexual concebida sob o signo de temor, disfarçadas em protecionismo rigoroso e altamente paternalista, corroborando para uma determinada concepção de pessoa, deficiência e sexualidade humana. A falta de informação e de um real conhecimento das necessidades das pessoas consideradas deficientes intelectuais perpetuem os estereótipos e preconceitos, negando-se a elas a chance de desenvolverem e viverem experiências no âmbito afetivo sexual.

Há um consenso entre os diversos autores pesquisados neste estudo de que as modificações próprias da puberdade acontecem naturalmente para a maioria das pessoas consideradas deficientes intelectuais, com exceção em alguns casos em que há severas alterações biológicas e fisiológicas. Os autores enfatizam que, em relação aos impulsos e desejos sexuais, essas pessoas manifestam necessidades, experiências e emoções semelhantes às das demais pessoas. (Bastos, 2005; Bastos \& Fidry, 2007; Bernstein, 1992; Dall'Alba, 2004; Denari, 2002; Eastgate, 2008; França Ribeiro, 2001; Glat \& Freitas, 1996; Katz \& Lazcano - Maia, 2001; Ponce, 2008). Desse modo, considera-se que o obstáculo para uma vida sexual amorosa satisfatória não está associado ao coeficiente intelectual ou a um possível problema neurológico presente na pessoa considerada deficiente intelectual, mas, principalmente, na dependência, 
infantilização e isolamento social que essas pessoas encontram-se expostas. No fato de que desde muito cedo são privadas do acesso aos prazeres do corpo e do livre manifestar dos impulsos sexuais, decorrente das crenças já descritas. Eastgate (2008) expõe que as pessoas consideradas deficientes intelectuais enfrentam uma ampla gama de questões relacionadas à sua sexualidade e poucas são suas oportunidades de compreenderem esse aspecto. Em decorrência, podem apresentar alguns comportamentos sexuais considerados socialmente inadequados, como exibicionismo e masturbação excessiva. No entanto, como bem asseveram Katz e Lazcano-Ponce (2008), sabe-se atualmente que essas pessoas são capazes de expressar adequadamente a sua sexualidade dentro de um contexto de respeito, com um comportamento socialmente aceitável em seu ambiente e conforme as normas estabelecidas se são dadas a elas oportunidades e apoio social adequados. França Ribeiro (2001) acrescenta que grande parte das pessoas consideradas deficientes intelectuais são capazes de saberem sobre papéis sexuais, vida em família, questões envolvidas no casamento e outras relacionadas à sua própria sexualidade. No entanto, faz-se necessário, para tal, que pais e educadores auxiliem essas pessoas na elaboração de conceitos e na aprendizagem de comportamentos aceitos pela sociedade em relação à sexualidade.

\section{Métodos}

\section{Participantes}

Para esta pesquisa de cunho qualitativo os participantes foram 10 pessoas consideradas deficientes intelectuais, composto por seis mulheres e quatro homens, que frequentavam uma escola especial no estado do Paraná. Sete participantes tinham idade entre 20 e 30 anos, uma das participantes tinha 43 e outros dois 16 anos. Todas essas pessoas moravam com seus familiares: pais, irmãos, cunhado, tios. Por uma questão ética foram utilizados pseudônimos para nomear os participantes da pesquisa, bem como as demais pessoas citadas nas falas dos participantes.

\section{Procedimentos e instrumentos}

Em um primeiro momento, foi explicado à direção da escola o objetivo da pesquisa para que autorizassem sua realização na instituição. Após aprovação, foi feita a seleção dos participantes sendo que os critérios levados em consideração na escolha foram: a facilidade de comunicação e entendimento das questões, pelo fato de a coleta de dados ser feita por meio de entrevistas a serem gravadas, e o interesse e motivação em participar da pesquisa. Um termo de consentimento livre e esclarecido foi apresentado e assinado pelos responsáveis legais dessas pessoas, e um termo de assentimento foi explicado para os participantes. As entrevistas, com duração mínima de trinta minutos, foram feitas de forma individual em uma sala apropriada para conservar a intimidade dos participantes e para que eles se sentissem à vontade em responder às perguntas. Estavam presentes apenas o pesquisador e entrevistado. Inicialmente, o pesquisador explicava o objetivo da pesquisa aos participantes que foram informados que a conversa seria gravada, mas seus depoimentos e identidades não seriam divulgados. Essas informações foram dadas em uma linguagem adequada a eles. Os limites dos participantes foram respeitados para não constrangê-los ou ofendê-los cabendo a eles dizerem apenas o que tivessem vontade. Foi solicitado aos participantes que falassem livremente sobre "namorar" e "fazer sexo". Com base em suas falas outras questões eram colocadas pelo pesquisador aos entrevistados de modo a clarificar o que eles compreendiam sobre estes temas.

\section{Compreensão das descrições}

0 método utilizado nesta pesquisa foi o fenomenológico (Martins \& Bicudo, 1999, Forguieri, 2004). As entrevistas foram gravadas e transcritas literalmente para serem analisadas de acordo com as premissas do método fenomenológico, realizado em quatro momentos, como apresenta Martins e Bicudo (1994):

1) Leitura geral do relato ou entrevista, sem interpretações, buscando familiarização com o fenômeno;

2) Identificação de unidades de significado, focalizando o fenômeno estudado, no caso a sexualidade da pessoa com deficiência intelectual;

3) Releitura dos textos, procura de apreensão mais abrangente do fenômeno estudado;

4) Reagrupamento dos elementos relevantes, transformando unidades de significado em uma descrição consistente da estrutura do fenômeno. 
As seguintes unidades de significado foram encontradas: 1) Namoro; 2) Experiência sexual; 3) Casamento.

\section{Resultados}

\section{Namoro}

Os participantes da pesquisa demonstraram que têm uma história para contar, uma representação e vivência a respeito do namoro. Dos dez participantes da pesquisa, apenas dois disseram que ainda não tiveram um relacionamento amoroso, todos os outros estavam ou já haviam namorado. Para essas pessoas o namorar foi definido como uma relação de amor com alguém especial, que se "ama de verdade". A amizade revelou-se como primeiro passo para o namoro. Para eles, primeiro era importante conhecer a pessoa. Na fase do namoro apareceram outros aspectos como o toque, carinho, pegar na mão, abraçar, beijar, relação sexual:

[...] namorar é estar junto de quem a gente gosta e ama de verdade; é pegar na mão, abraçar, também conversar. No começo é mais conversa para saber o que a pessoa gosta, o que faz, se mora perto ou longe... Namorar também é sair bastante, ir para restaurante, a maioria das pessoas saem para "balada" para dançar [...] (Álvaro).

[...] para gente poder namorar tem que conhecer a pessoa direito, saber como a pessoa é, se é simpática, se é carinhosa, se é brava, educada, não pode ser ciumenta. Depois, namorar é abraçar, pegar na mão, um beijinho. É quando um rapaz convida a moça para ir ao cinema, para passear [...] (Marcela).

Ao falarem de suas experiências pessoais, os participantes dessa pesquisa revelaram que a sua forma de namorar restringia-se a conversar, pegar na mão, abraçar, beijar no rosto ou na boca. Não disseram ter um contato mais íntimo, uma relação sexual com seu (sua) parceiro (a). Compreendeu-se também que para os participantes desta pesquisa, muitas vezes o (a) namorado (a) é visto como um (a) amigo (a) especial com quem se sentem bem e gostam de conversar. 0 companheirismo, revelado nas falas por alguém que "está sempre junto", que "oferece apoio" e se interessa pelos sentimentos do outro, foi ressaltado pelos participantes. Para eles, a companhia do (a) seu(sua) namorado (a) parece ser o fator mais importante da relação, mas reconhecem que para o desenvolvimento de uma relação afetiva de namoro, é necessário ir além do sentir-se bem com o outro, pois envolve outros aspectos como vontade de abraçar e beijar:

[...] olha melhor coisa que tem, eu gosto mais dele (namorado) e das meninas, minhas amigas. Meu namorado me oferece muito apoio, é o único homem que é meu amigo, o único amigo e namorado, eu gosto mais dele, porque ele me dá muito apoio, a gente conversa, ele está cansado vem e senta perto de mim, pergunta da minha mãe, me apoia que nem minhas amigas, mas ele é diferente das meninas, ele é mais carinhoso, dá carinho no rosto, beija [...] (Lílian).

[...] Ah eu gostava da Denise (namorada)! Pena que ela foi embora! Eu sinto muita falta dela, muita falta mesmo, porque ela era gente boa, companheira. Era bom conversar com ela, beijar, mas fazer o quê? Ela foi embora [...] (Dione).

Por meio das histórias dos participantes da pesquisa percebeu-se que suas questões são como a de qualquer pessoa que deseja ter um relacionamento afetivo de namoro. Sentimentos relacionados à autoimagem, autoestima e vaidade foram apresentados pelos participantes ao falar sobre namoro:

[...] eu me arrumo, faço o possível para poder arranjar um namorado, porque andar de qualquer jeito não dá. É importante andar bem arrumada, jovem tem que andar "chique" também né? [...] (Julia).

[...] quando o Victor me chama de gorda eu não gosto, eu fico triste, chateada, porque eu não gosto. Eu não sou gorda, eu estou fazendo regime, estou emagrecendo. Eu fico triste, chego em casa e choro, fico no quarto chorando [...] (Lílian).

[...] ah, eu me acho feio, me sinto feio. Não tem como explicar. É esquisito, ninguém acha eu bonito, então eu não me acho bonito mesmo, me acho feio. [...] (Felipe).

Nos relacionamentos, por mais "simples" que possam parecer, emergem questões comuns a todas as pessoas como a fidelidade, o ciúme, a confiança, o cuidado:

[...] ah às vezes meu namorado fica perto de outras "gurias". Eu fico chateada porque se ele gosta de mim tem que me respeitar do jeito que eu sou, ficar do meu lado, confiar, não dar bola para as outras meninas. 
O que eu mais detesto é traição. $O$ cara finge que gosta da namorada, mas não gosta, gosta de outra, fica correndo atrás das meninas. Meu namorado não dá bola para mim, ele finge que eu não existo, ele me esquece [...] (Marcela).

[...] É santinha (namorada), mas nem tanto! Ela é "assanhadinha"! Eu tenho ciúmes quando ela fala com os outros homens. O Miguel quando a abraça faz eu ficar preocupado (risos). Eu cuido dela dando umas olhadas por aí (risos) quando eu estou conversando com alguém eu fico só de olho. Quando ela está com as amigas não vem conversar comigo. Eu queria que ela viesse conversar comigo mais, mas ela não vem. Dá vontade de falar: " - Em vez de suas amigas, porque não vem conversar comigo? Você prefere mais suas amigas do que eu?" [...] (Leonardo).

Percebeu-se o quanto é importante para a pessoa com deficiência intelectual ter um vínculo afetivo e o quanto faz bem viver uma relação de namoro, que aqui adquire diferentes significados - pode ser conversa, toque, abraço, beijo. Muitas vezes é bom namorar pelo simples fato de ter alguém para conversar, uma companhia, o que conta nesse caso é a qualidade e o benefício de poder experienciar uma relação, de permitir relacionar-se com o outro ao seu modo, ao seu jeito, ter seus sentimentos reconhecidos e valorizados.

\section{Experiência sexual}

Dentro da área da sexualidade percebeu-se que poucos entrevistados falaram sobre o ato sexual propriamente dito. Alguns disseram nunca terem tido uma relação sexual, outros nem mesmo comentaram. Percebeu-se que, sobre assuntos ligados ao sexo, os participantes da pesquisa preferem não comentar com outras pessoas. Esse não falar sobre sexo pareceu ser proveniente do fato de que muitos não se sentiam confortáveis ao falar de tais aspectos, outros falavam, mas ficavam constrangidos e utilizavam termos como "essas coisas", "sobre isso" em lugar da própria palavra "sexo". Soma-se a isso o fato de que falar sobre tais aspectos adquire um sentido de proibição, com risco de punição, sendo que as principais instituições a fazer valer essa regra social são a família e a escola.

0 desejo de se relacionar amorosa e sexualmente é comum em todas as pessoas, não sendo diferente para os entrevistados. Apesar de poucos participantes falarem a respeito de relação sexual, alguns demonstraram vontade de concretizar essa experiência. $\mathrm{O}$ ato sexual teve um sentido de intimidade, seria um encontro de duas pessoas que se gostam e têm um desejo comum. A importância de se considerar as características pessoais e o fato de que, para acontecer o ato sexual, o outro precisa querer, revelou-se na fala dos participantes:

[...] depende da minha namorada, se ela falar "quero fazer sexo" eu faço, eu quero fazer sexo, mas a gente não tem lugar para fazer também [...] (Leonardo).

[...] Eu não, nem mexo com isso (sexo). Sei lá, de vez em quando eu tenho vontade de fazer sexo, mas por enquanto não, porque não posso. Só faria sexo com a Denise (namorada) se ela quisesse, mas não quis. Ela é a única pessoa com quem queria fazer sexo [...] (Dione).

Ao falar sobre relacionamento sexual, os participantes dessa pesquisa trouxeram informações sobre gravidez, métodos de contracepção e doenças sexualmente transmissíveis:

[...] acho que para fazer sexo precisa ter camisinha para não pegar Aids, acho que para não engravidar também, mesma coisa, tem que usar camisinha e as mulheres tomarem remédios. Eu sei por que todas as pessoas falam e comentam isso. Todas as pessoas usam camisinha, tem que usar camisinha mesmo. Eu ouço umas pessoas falarem que é importante isso [...] (Felipe).

[...] eu tenho camisinha para não pegar Aids e para não ter filho. Tenho camisinha aqui comigo e em casa, só que minha mãe não sabe [...] (Leonardo).

Convém ressaltar que poucos participantes trouxeram informações sobre essas temáticas, provavelmente pelo desconhecimento, e os que falaram a respeito demonstraram incerteza diante de suas compreensões. As informações podem ser consideradas "superficiais", no sentido de pouco esclarecimento sobre o assunto. Não parece haver uma fonte segura que traga as informações de forma correta e com possibilidade dessas pessoas retirarem suas dúvidas.

\section{Casamento}

Dentre os diversos valores sociais concernentes às relações afetivo-sexuais, um aspecto frequentemente colocado pelos participantes, ao falar sobre 
namoro, foi o casamento. Os sonhos e expectativas de construção de uma vida própria, como casar e ter filhos, faz parte das aspirações da pessoa com deficiência intelectual. Nas entrevistas, revelaram seus desejos e desilusões, alegrias e tristezas, inseguranças e certezas, a recusa à solidão. Os participantes querem coisas iguais como tantas outras pessoas. 0 desejo de casar surge principalmente nas mulheres, mas os homens também falaram sobre o assunto:

[...] aí a Karla falou: "- O Álvaro é bonito por que você não casa com ele?". Eu falei: "- Eu não posso casar com ele, só namorar!". É porque ele não que casar, só quer namorar. Falei para ele me pedir em casamento, ele falou: "- Talvez quando eu for mais velho eu caso com você, eu tenho primeiro que trabalhar" [...] (Lucia).

[...] sinto falta da Denise (namorada). Uma vez ela falou para mim: "- Vamos casar ou amigar?" Ela disse que dava um jeito. Eu queria amigar, mas não deu certo, se eu amigasse poderia namorar, beijar na boca, abraçar [...] (Dione).

O casamento apareceu ligado a um futuro distante. Apesar do desejo, essas pessoas ressaltaram que antes de casar precisariam arrumar um emprego. Esse aspecto da estabilidade econômica ligada ao casamento se revelou nas falas dos participantes:

[...] houve uma vez que ele (namorado) pediu minha mão em casamento. Eu não aceitei sabe? Eu não quero! Porque meu namorado está desempregado agora, não dá para casar. Ele está desempregado, saiu do mercado que trabalhava. Para casar precisa de um emprego sabe? Como é que vai ter um marido desempregado! Ninguém vai aguentar muito tempo! Se ele tivesse um emprego até que eu casava, agora desempregado, não dá! [...] (Amanda).

[...] eu sei que eu gosto bastante dela (namorada), só que casar é difícil. Sem trabalhar não dá. Se eu tivesse dinheiro eu casaria e teria filhos, um pelo menos, mas minha namorada não quer ter filhos [...] (Leonardo).

Ainda em relação ao casamento, outro aspecto que se revela é a clara divisão de papéis homem/ mulher e esposa/marido. Os papéis sexuais apareceram divididos: ao homem cabe a função de trabalhar para casar e sustentar a família; à mulher a obrigação de cuidar da casa e dos filhos, o que não seria uma opção, mas um fato principalmente para as mulheres entrevistadas:
[...] quando ele (o namorado/marido) vir a mãe tem que me ensinar a fazer comida em casa. Eu fiz arroz esses dias. Ah, eu tenho vergonha de não saber cozinhar, meu marido vai ficar morrendo de fome? Eu quero cozinhar pro marido, é feio uma mulher não saber cozinhar, lavar roupa, um monte de coisa, limpar a casa até que eu sei. Para o homem é feio não cuidar dos filhos. Acho que tem pai que cuida, mas têm muitos que "deixam para lá" [...] (Julia).

[...] tem que casar para ter filho, para viver junto com a família. Eu quero casar, quero cuidar da minha casa, cuidar do meu marido, cuidar da roupa dele, ter meu filho, quero ter uma menina, quero adotar uma menina [...] (Lílian).

[...] meu irmão se ele não casar é "viado", porque ele já tem vinte anos. Ele trabalha, já tem até dinheiro, é bom que case, arranje uma casa. Ele fica trabalhando e a mulher dela fica na casa fazendo comida e lavando a roupa dele [...] (Amanda).

Além disso, o casamento apareceu ligado à maternidade/paternidade e ao fato de que ter filho seria uma consequência e obrigação e não uma opção dentro de uma relação conjugal:

[...] quando você namora rola sexo, mas comigo não, é diferente. Eu não quero, prefiro morrer e ficar solteira. Ficar solteirona sabe? Eu vou ficar solteirona um dia, quando eu ficar mais velha, porque eu não vou casar, é muito trabalho, tem que ter filho, tem que cuidar do filho: dar banho, dar mamadeira, e eu não quero isso nem brincando [...] (Amanda).

[...] a hora de noivar é a hora que for casar. Sexo só depois do casamento. Daí a mulher tem que engravidar. Antes do casamento não pode engravidar, mais depois do casamento pode. Se fizer sexo antes do casamento fica tudo errado! Eu não quero ter filho não, nem fazer sexo, ter filho é ruim [...] (Marcela).

Dessa forma percebeu-se uma linearidade dos fatos para os participantes do estudo: todas as pessoas devem namorar casar e ter filhos e isso seria uma "ordem natural a ser respeitada". 0 casamento apareceu ligado ao sexo e este diretamente relacionado à gravidez como se invariavelmente ao ter relações sexuais a mulher engravidasse.

\section{Discussão}

Neste estudo, percebeu-se que os participantes possuem pouca experiência de namoro e suas 
representações sobre esse aspecto podem ser consideradas, em diversos momentos, como "fantasiosas", "infantilizadas" e "ingênuas". O que veio de acordo com os resultados encontrados por Glat e Freitas (1996) em um estudo clássico no campo da sexualidade da pessoa considerada deficiente intelectual. Não obstante, é preciso considerar que essas representações não estão relacionadas a um problema neurológico, mas a forma como essas pessoas são percebidas pela sociedade, familiares e profissionais: como "eternas crianças". (Dall'Alba, 2004; Denari, 2002; França Ribeiro, 2001; Glat \& Freitas, 1996; Maia, 2001). Não se possibilita a essas pessoas amadurecerem em relação a sua sexualidade. Não há, em muitas situações, a preocupação de trabalhar no sentido de promover para que desenvolvam suas relações afetivas dentro de suas necessidades para serem mais felizes e satisfeitas em seus relacionamentos. Soma-se a isso, o isolamento social que muitas destas pessoas vivem e resulta na pouca oportunidade de se envolverem afetivamente e com isso aprenderem e compreenderem sobre as questões ligadas a sua sexualidade e afetividade. Ao mesmo tempo, os participantes, apesar da pouca experiência, demonstraram compreender a importância de conhecer a pessoa que namora e do companheirismo em uma relação afetiva de namoro. Também sabem que no namoro acontecem beijos e que podem acontecer relações sexuais. Como colocam Katz e Lazcano-Ponce (2008), é importante trabalhar com as pessoas consideradas deficientes intelectuais o conceito de namoro, o significado dessa relação e a responsabilidade em se envolver em um relacionamento amoroso por meio de um compromisso que se estabelece com o (a) parceiro (a). Com isso, essas pessoas podem desenvolver um senso de respeito para com o (a) namorado (a) e compreenderem os sentimentos que surgem como consequência desta prática. Podem, desse modo, tornar-se responsáveis por seus comportamentos sexuais.

O espaço educacional revelou-se como o local onde essas pessoas têm as maiores possibilidades de interação social, muitas vezes o único local de encontro com pessoas além do ambiente familiar. Muitos dos namoros ocorrem apenas no espaço escolar, sendo que vale ressaltar que na escola é proibido namorar, apenas pode pegar na mão e abraçar, mas sem beijar. Diante disso, é interessante colocar que, de acordo com Moukarzel (2003), ao proibir seus alunos de se relacionarem amorosamente, a escola pode diminuir ainda mais as oportunidades desses jovens. Isso pode dificultar o estabelecimento de vínculos afetivo-sexuais, impedindo-os de aprender a desenvolver com responsabilidade relacionamentos amorosos fundamentais para a compreensão de sua própria sexualidade. Também é relevante repensar os programas das escolas voltados às pessoas adolescentes e adultas consideradas deficientes intelectuais, como os participantes deste estudo. A ênfase deve ser em programas que promovam a inclusão escolar, social e no mundo do trabalho, para que essas pessoas, dentro de suas possibilidades, possam atingir independência familiar, social e econômica.

$\mathrm{Na}$ sociedade atual, falar sobre sexo desperta um saber curioso, de desvelamento, algo proibido e encoberto por tabus, evidenciando paradoxos no tratamento dessas questões. De um lado existe um racionalismo organicista propagado pela ciência positivista e legitimado pela escola. Do outro, o moralismo cristão repressor do prazer sexual. E ainda um terceiro aspecto que se traduz no erotismo banalizado, comercial, apelativo e preconceituoso difundidos pelos meios de comunicação (Moukarzel, 2003). Dessa forma, falar sobre sexualidade gera, muitas vezes, dificuldades que se intensificam em relação à pessoa considerada deficiente intelectual, sendo que esse assunto se apresenta como um conflito para seus pais, os profissionais que trabalham em sua habilitação, e para eles próprios. Sobre o ato sexual propriamente dito, poucos participantes trouxeram informações e os que falaram sobre isso disseram nunca terem tido uma relação sexual, apesar de demonstrarem desejo quanto a esse aspecto. Semelhante a esse dado, em um estudo sobre a sexualidade das pessoas consideradas deficientes intelectuais, Glat e Freitas (1996) constaram que nenhuma das mulheres entrevistadas haviam tido relações sexuais, apesar de estarem namorando, e poucos homens disseram já terem tido a experiência, porém nenhum deles levava uma vida amorosa e/ou sexual ativa e constante. Como afirmam as próprias autoras, estes dados demonstram o grau de infantilização existencial que essas pessoas estão condenadas e a omissão dos pais e profissionais que subestimam a condição e desejo desses indivíduos terem relacionamentos afetivos. Por meio do artigo de Conod e Servais (2008), nota-se que em outros países há vários estudos publicados cujo foco é avaliar questões médicas e educacionais sobre a vida e 
a saúde sexual das pessoas com deficiência intelectual. No Brasil há carência de estudos semelhantes, o que demonstra pouca preocupação do governo e das instituições de saúde e educação com essa questão fundamental ao se falar de uma sociedade em busca da inclusão da pessoa com deficiência.

Ao remeter-se a aspectos relacionados à sexualidade da pessoa considerada deficiente intelectual surge uma dúvida comum, principalmente por parte dos pais, ao reconhecerem que esses indivíduos possam ter relações sexuais, se eles serão capazes de cuidarem de um filho. A partir dessa questão emergem outras como: qual dos métodos anticoncepcionais seria o mais adequado para garantir a saúde da pessoa considerada deficiente intelectual, bem como evitar uma gravidez indesejada; se a intervenção cirúrgica é uma medida ética ou não para garantir essa segurança; até que ponto os pais podem interferir na vida sexual de seus filhos com deficiência. Esses e outros temas importantes e polêmicos, no Brasil pouco debatidos, devem ser tratados com cuidado para que a pessoa com deficiência intelectual não seja prejudicada em sua autonomia e não sofra por decisões tomadas pelos outros que não respeitem sua singularidade e seu direito de escolha. Como colocam Glat e Freitas (1996), frequentemente a pessoa considerada deficiente intelectual é vista com uma aparente incapacidade de analisar sua vida e expressar seus sentimentos. Frente a esse mito, a família e os profissionais fazem escolhas e tomam decisões pela pessoa considerada deficiente intelectual, o que prejudica a capacidade das mesmas tornarem-se independentes. Ao contrário, quanto maior for o incentivo à autonomia e dependência dessas pessoas, maior é a probabilidade de que estabeleçam relações amorosas e até mesmo sexuais.

Como consequência da pouca possibilidade de a pessoa considerada deficiente intelectual falar sobre suas questões relativas à sexualidade, o que dificulta a compreensão destes aspectos por elas, e das poucas informações que recebem de seus familiares e dos profissionais que trabalham com essas pessoas, percebeu-se que seus conhecimentos sobre sexualidade, funções corporais, reprodução, doenças sexualmente transmissíveis, gestação, nascimento e uso de métodos anticonceptivos são bastante precários e superficiais. Diante disso, um aspecto importante, em relação à sexualidade dessa população, é a necessidade de uma orientação sexual. Segundo Bernstein (1992), nossa sociedade é constantemente bombardeada por revistas eróticas, pela excitação da televisão, por piadas sobre sexo e notícias de abusos sexuais nos jornais. As pessoas consideradas deficientes intelectuais não estão de forma alguma excluídas dessas barragens de mensagens complexas, conflitantes e estimulantes sobre a sexualidade contemporânea, e veem-se esses indivíduos lutarem com as mesmas questões que são tão difíceis para pessoas mais autossuficientes. No entanto, como destaca Pinheiro (2004), normalmente as orientações sexuais direcionadas à pessoa considerada deficiente intelectual são para eliminar comportamentos julgados inadequados e não têm como objetivo o resgate da identidade sexual com privilégios e responsabilidades que implicam sua vivência, nem tão pouco a possibilidade de oportunizar espaços para interagir, retirar dúvidas e expor seus pensamentos. Postula-se que, antes de se realizarem programas de educação sexual para essas pessoas, é necessário investigar seus reais conhecimentos, experiências, sentimentos, atitudes e necessidades para, depois, com base nesses dados, realizar um programa que atenda de fato as necessidades dessa clientela. Isto também é importante no que diz respeito ao abuso sexual, frequente nessa população, pois, como coloca França Ribeiro (2001), a ameaça da vulnerabilidade dos deficientes à exploração sexual é uma questão crítica que deve ser considerada, mas o medo que se tem de lidar com a sexualidade dessas pessoas e a falta de informação nesta área, ao contrário de oferecer proteção a essas pessoas, deixam-nas impossibilitadas de saberem decodificar os sinais de perigo que possam antecipar este tipo de situação. Ao não possibilitar um diálogo sobre os aspectos da sexualidade desses indivíduos, os pais acabam não os ensinando a dizerem não, deixando aberto o caminho para as mais variadas formas de exploração afetiva.

Mourkazel (2003) ressalta que o casamento, como instituição consagrada na cultura cristã, habita o imaginário afetivo-sexual de qualquer pessoa, não sendo diferente para a pessoa considerada deficiente intelectual, que assimila as regras e valores morais do seu contexto social. Mas, para a autora, o mesmo imperativo ideológico que incorpora tais conceitos a essas pessoas, impõe também os dispositivos de exclusão para a vivência compartilhada de seus desejos. No tocante a essa questão, dois imperativos de negação se sobrepõem: de um 
lado as injunções morais de negação do prazer e, de outro, as reminiscências teóricas sobre o caráter degenerativo da deficiência. Na atualidade mais um fator vem se agregar a tais impedimentos: as questões de ordem econômica na manutenção da vida familiar. De fato, observou-se que o desejo de casar existe por parte de alguns dos participantes da pesquisa, principalmente das mulheres, porém ele estaria ligado a um futuro distante. A questão econômica, apesar de corresponder a um fator real, seria limitante, pois o homem deve trabalhar para casar, o que não corresponde à realidade de grande parte dessa população. Da mesma maneira, em muitos casos, essas pessoas não são vistas como capazes de gerenciar uma família. Apesar disso, os papéis sexuais apareceram bem divididos na compreensão dessas pessoas: ao homem cabe a função de trabalhar para casar e sustentar a família e à mulher o papel de cuidar da casa e dos filhos, o que não seria uma opção, mas um fato em si para muitas dessas jovens. 0 casamento foi visto pelos participantes do estudo como uma obrigação e não uma possibilidade de viver com outra pessoa, opção que pode ou não ser viável para eles. Essa percepção é sustentada pela sociedade que apresenta o casamento como um compromisso e uma responsabilidade por parte do casal que deve ter uma estabilidade econômica para poder sustentar a família, pois o que se espera é que venham a ter filhos. Dentro dessa concepção ideológica, a pessoa considerada deficiente intelectual encontra dificuldades tanto para namorar quanto para casar, afinal, nem todos têm condições de cuidar da família e um emprego de onde provém seu sustento. A pessoa considerada deficiente intelectual tem o direito de decidir sobre sua vida, e seus desejos e vontades devem ser levado em consideração. Elas devem participar das discussões e decisões que dizem respeito a sua vida de modo a serem mais autônomas e independentes. Assim, por exemplo, como muitas mulheres desejam ter filhos, as participantes deste estudo também demonstraram o desejo, e isto não deve ser tirado delas, mas debatido com as mesmas. 0 essencial é auxiliar essas pessoas na compreensão de que ter um filho é uma opção e não obrigatoriedade, e que não necessariamente todas as mulheres precisam ter filhos. Mostrar as consequências de uma criança para a vida de uma pessoa, as responsabilidades e cuidados que devem ser assumidos é fundamental.
Convém ressaltar que as orientações e intervenções em relação à pessoa considerada deficiente intelectual, e isto vale para a sexualidade também, devem se pautar não em classificações que consideram apenas o nível intelectual, constatado por meio de testes de inteligência, mas em modelos que considerem a pessoa em seus diversos aspectos e inserida em seu contexto. A Associação Americana de Retardo Mental (AAMR, 2006) enfatiza os sistemas de apoios como medidas mais eficazes no trabalho com as pessoas consideradas deficientes intelectuais. Esses apoios se aplicam às áreas do desenvolvimento humano, ensino e educação, vida doméstica, vida comunitária, trabalho, saúde, segurança, comportamento, vida social, proteção e defesa. Tais sistemas são classificados de acordo com a necessidade de cada pessoa em:

a) apoios intermitentes, disponibilizados apenas em momentos necessários;

b) limitados, quando a assistência é temporal de curta duração com apoio mantido até sua finalização;

c) extensivos, oferecidos regularmente e periodicamente;

d) pervasivos, quando constantes, estáveis e de alta intensidade. Portanto, trata-se de olhar o sujeito em sua integralidade e singularidade, não como mais um indivíduo classificado em uma determinada categoria, neste caso, de deficientes intelectuais.

\section{Considerações finais}

Este estudo buscou revelar que, ao contrário do mito de que as pessoas consideradas deficientes intelectuais são incapazes de expressar seus sentimentos, esses sujeitos podem não apenas falar, mas compreender, com apoio familiar e educacional adequados, as diversas questões que surgem relacionadas à sua afetividade. No campo da sexualidade, apesar de todas as restrições e proibições, por parte principalmente dos familiares e da escola, essas pessoas mostraram que têm desejo de namorar, casar, fazer sexo, que aqui pode ser relação sexual propriamente dita, masturbação, toque, abraço ou simplesmente conversa, mas evidenciou-se que nem sempre são reconhecidas e valorizadas nelas essas aspirações. Isso evidencia a 
importância dos profissionais da saúde e educação que trabalham com essa população oferecerem a oportunidade para que essas pessoas falem sobre aquilo que sentem e experienciam a respeito de suas relações afetivas, valorizando suas opiniões e suas compreensões em relação a esse aspecto.

$\mathrm{Na}$ contemporaneidade, ao se pensar na inclusão da pessoa considerada deficiente intelectual, revela-se fundamental uma abordagem global das questões relacionadas à sua saúde sexual. Durante anos, a atenção sobre a sexualidade desses sujeitos era exclusivamente centrada na esterilização cirúrgica como parte dos programas voltados a essa população. Essa medida era decorrente dos altos índices de abuso sexual entre essas pessoas como necessidade de prevenção de gravidez não planejada. Contudo, além destas questões, outros aspectos fundamentais e muitas vezes negligenciados ao se falar da saúde sexual desta população precisam ser debatidos e considerados ao se pensar em serviços que contemplem a sexualidade desses sujeitos, tais como: prevenção de doenças sexualmente transmissíveis, controle de natalidade, planejamento familiar, métodos de higiene pessoal e genital, abuso sexual, entre outros fatores. Também, é necessário trabalhar conceitos como namoro e relação sexual. Por isso, é fundamental ampliar as discussões em torno dessa temática e considerar medidas que tenham um alcance maior no que diz respeito à sexualidade desses indivíduos para que ocorra um redirecionamento dos serviços educacionais e terapêuticos oferecidos a eles, em um trabalho que envolva os profissionais da área médica, com conhecimento relacionado a essa população, a equipe educativa, os familiares e, de modo especial, a pessoa considerada deficiente intelectual.

Há muito a se investigar com relação à temática deste estudo. Outras pesquisas concernentes às questões aqui apresentadas precisam ser realizadas. $\mathrm{Na}$ atualidade, surge a necessidade de políticas públicas que visem à promoção da saúde e à qualidade de vida das pessoas consideradas deficientes intelectuais com intuito de promover sua independência familiar, social e econômica. Nesse sentido, muito ainda deve ser discutido e trabalhado no Brasil para que o país tenha condições de oferecer serviços que promovam a valorização e inclusão da pessoa considerada deficiente intelectual.

\section{Referências}

Amaral, L. A. (1994). Pensar a diferença/deficiência. Brasília: CORDE.

Associação Americana de Retardo Mental - AAMR. (2006). Retardo mental: Definição, classificação e sistemas de apoio. Porto Alegre: Artmed.

Associação Psiquiátrica Americana - APA. (1994). Manual diagnóstico e estatístico de transtornos mentais (DSM-IV). Porto Alegre: Artmed.

Bastos, O. M. (2005). Entre o desejo e o medo de ver o filho adolescer: Narrativas de pais de adolescentes com deficiência mental. Tese de doutorado em Saúde da Criança e da Mulher, Instituto Fernando Figueira; Fundação Oswaldo Cruz, Rio de Janeiro.

Bastos, O. M., \& Deslandes, S. F. (2005). Sexualidade e o deficiente mental: Uma revisão bibliográfica. Ciência e Saúde Coletiva, 10(2), 389-396.

Bastos, O. M., \& Fidry, D. (2007). Adolescente com deficiência mental: Abordagem dos aspectos sexuais. Adolescência \& Saúde, 4(3), 30-33.

Bernstein, N. R. (1992). Sexualidade em adolescentes deficientes mentais. In M. Sugar (Org.). Adolescência atípica e sexualidade (pp. 51-61). Porto Alegre: Artmed.

Conod, L., \& Servais, L. (2008). Sexual life in subjects with intellectual disability. Salud Publica Mexico, 50(2), 230-238.

Dall'Alba, L. (2004). Educação Sexual da pessoa caracterizada como Deficiente Mental: Construção da autonomia. In L. Bianchetti, I. M. Freire (Org.). Um olhar sobre a diferença: Interação, trabalho e cidadania. (pp. 181-223). Campinas: Papirus.

Denari, F. E. (2002). Sexualidade e deficiência mental: Reflexão sobre conceitos. Revista Brasileira de Educação Especial, 8(1), 9-14.

Eastgate, G. (2008). Sexual health for people with intellectual disability. Salud Publica Mexico, 50(2), 255-259.

Egypto, A. C. (2003). Orientação sexual na escola: Um projeto apaixonante. São Paulo: Cortez.

Forghieri, Y. C. (2004). Psicologia fenomenológica: Fundamentos, métodos e pesquisas. São Paulo: Pioneira. 
França Ribeiro, H. C. (2001). Sexualidade e os portadores de deficiência mental. Revista Brasileira de Educação Especial, 7(2), 11-26.

Glat, R., \& Freitas, R. C. (1996). Sexualidade e deficiência mental: Pesquisando, refletindo e debatendo sobre o tema. Rio de Janeiro: Sette Letras.

Goffman, E. (1988). Estigma: Notas sobre a manipulação da identidade deteriorada (4a ed.). Rio de Janeiro: LTC.

Katz, G., \& Lazcano-Ponce, E. (2008). Sexuality in subjects with intellectual disability: An educational intervention proposal for parents and counselors in developing countries. Salud Publica Mexico, 50(2), 239-254.

Maia, A. C. B. (2001). Reflexões sobre a educação sexual da pessoa com deficiência. Revista Brasileira de Educação Especial, 7(11), 35-46.

Martins, J., \& Bicudo, M. A. V. (1994). A pesquisa qualitativa em psicologia: Fundamentos e recursos básicos. São Paulo: Moraes.
Moukarzel, M. G. M. (2003). Sexualidade e deficiência: Superando estigmas em busca da emancipação. Dissertação de Mestrado em Educação, Faculdade de Educação da Universidade Estadual de Campinas, Campinas.

Omote, S. (1994). Deficiência e não deficiência: Recortes do mesmo tecido. Revista Brasileira de Educação Especial, 1(2), 65-73.

Pinheiro, S. N. S. (2004). Sexualidade e deficiência mental: Revisando pesquisas. Psicologia Escolar e Educacional, 8(2), 199-206.

Tomazini, M. E. A. (2004). Expatriação social e a segregação institucional da diferença: Reflexões. In L. Bianchetti \& I. M. Freire (Org.). Um olhar sobre a diferença: Interação, trabalho e cidadania (pp. 111-133). Campinas: Papirus. 